\title{
Inspiração e transfusão
}

\section{Miguel Miranda}

médico e escritor

Resumo: Neste ensaio, partimos da experiência de escritor médico, para uma reflexão sobre os modos como a literatura e a medicina se complementam no entendimento dos seres humanos. Afirma-se o pendor humanista da Medicina, não obstante a parafernália tecnológica e burocrática da atividade médica actual. E propõem-se respostas para muitas das questões que o tema suscita: o que leva os médicos a escrever, sobre o que escrevem eles, de onde lhes vem a inspiração. No final, uma conclusão irrefutável: Medicina e Literatura são duas das mais belas artes do mundo.

Palavras-chave: literatura, medicina, vida, humanismo, beleza

\begin{abstract}
In this essay, we consider the experience of a doctor/ writer, thinking through the ways in which literature and medicine complement each other for an enhanced perception of human beings. The humanist dimension of Medicine is thus stressed, despite the technological and bureaucratic paraphernalia of current medical activity. Several answers are suggested for many of the questions that such topic raises: what makes doctors write? What do they write about? Where does their inspiration come from? In the end, an irrefutable conclusion is reached: Medicine and Literature are two of the most beautiful arts in the world.
\end{abstract}

Keywords: literature, medicine, life, humanism, beauty

A inspiração é o que é, apenas metade do processo. Nada vale sem a competente expiração. Na literatura como na vida, o que nos mantém vivos é o vento da respiração, esse movimento de maré entre memórias, algumas ainda nem sequer registadas, apenas efabuladas. Esse moto contínuo de inalação (absorção) e exalo (emissão), é a base da criação literária. 
O escritor é um ser transfuso, mete para a veia tudo o que o cerca: ambientes, épocas, paletas de cores, gente, personagens, vozes, tiques, histórias. Assim transfundido, é capaz de inventar histórias e deitá-las de borco num texto na impunidade da criação literária.

0 processo de criação literária é misterioso e controverso. A criação poderá surgir do nada, à custa de imaginação pura - o que poderá ser um processo aparentado dos delírios dos psicóticos. Deste ponto de vista, a semelhança entre o escritor e o louco é patente, diferindo apenas no grau de controlo e consciência dos delírios de um e de outro.

Adaptando a lei de Lavoisier sobre a conservação da matéria, no que se refere à matéria literária, diria que: "No universo da literatura, nada se cria, nada se perde, tudo se transfunde".

Já que falamos de leis da Física e a sua correlação com a literatura, lembremos Newton, que descobriu e postulou que a atração entre dois corpos varia na razão inversa do quadrado da distância. Na literatura esta lei de Newton tem sábia aplicação, que o digam os lábios dos amantes.

Na criação literária os conceitos de Lavoisier, Newton, a constante de Planck e o princípio de incerteza de Heisenberg existem em sentido figurado, são corvos pendurados nos ramos do pensamento, à espera. Do momento e da luz.

Há um momento e uma luz para desencadear a escrita dentro do escritor. Um momento mágico, de espanta-corvos.

O escritor, assim iluminado, usa a efabulação para transgredir todas as leis, regras, distâncias ou arcos temporais. Os textos saem-lhe transfundidos, ou mais propriamente, refundidos: são feitos de uma amálgama mental, cujas características são:

A escrita é feita com meia de memória, três quartos de imaginação, tudo batido ao ritmo de inspiração e expiração, até ganhar ponto, usando uma base de transpiração. Depois, serve-se a gosto.

A memória não tem uma localização cerebral única. As memórias vagueiam entre o córtex e o hipocampo, e são barro pronto a ser moldado. 0 escritor ao usar a memória para escrever, usa várias assoalhadas do seu cérebro. E ainda the acrescenta a imaginação, indispensável ao processo da criação literária. Não se sabe se a imaginação e a memória estão localizadas nos mesmos locais do cérebro, pensa-se que não, embora haja relação entre elas. O local mais literário do cérebro, o hipocampo, parece ter papel fundamental neste processo de organização do pensamento em que consiste a criação literária.

É bom de imaginar a imaginação a cavalgar memórias no hipocampo, partindo à desfilada pelos circuitos neuronais até formarem histórias e mundos no ecrã do pensamento do escritor. Se não for assim que as coisas acontecem, no meu mundo literário, passam a ser. 


\section{Literatura e Medicina}

Literatura e Medicina são duas formas de entender o homem, as relações humanas e o Mundo.

Os médicos possuem o poder de curar, de salvar as pessoas da morte, da doença e do sofrimento.

Os escritores estão investidos do poder da imortalidade, do poder de fazer regressar os mortos à vida, de viajar no tempo e de viajar para qualquer lugar do Mundo ou do universo a uma velocidade superior à da luz.

Quando estas duas condições se reúnem num só ser (médico e escritor) este poderá ser elevado à condição de divindade.

$\mathrm{Na}$ realidade, as coisas não se passam assim. Veremos mais à frente que estes casos de dupla personalidade e duplicidade de funções, são mais deletérios e menorizadores do indivíduo, do que elevadores.

A profissão médica é a mais bonita do mundo. Digo isto fazendo uma declaração de interesses: sendo médico e amando a minha profissão, é natural que esta minha afirmação seja hiperbólica e deva sofrer algum desconto. Mas que é a mais bonita, é. De tal modo isto é verdade que nem necessita de demonstração.

Por outro lado, ser escritor é professar a arte mais bonita do universo - aquela que se superioriza a todas as outras. Afirmo isto, fazendo outra declaração de interesses: sendo eu escritor e não tendo qualquer jeito, apetência, pulsão ou habilidade para outra arte, desde a música, à pintura, escultura ou outras, digo o que digo, valendo o que vale. A minha inaptência para outras artes para além da escrita foi comprovada desde muito cedo: no ensino secundário, consegui a proeza de ter nota negativa a Desenho e fa façanha iniguaqlável de ter explicações a essa disciplina, que é uma coisa difícil de imaginar. A minha incursão no mundo da música, não foi melhor: tentei aprender acordeão, quando tinha uns nove anos. Tenho gravadas na memória duas cenas altamente marcantes: quando me instalaram no meio do palco do teatro S. João, de acordeão em riste, para tocar uma peça musical, na festa de fim de ano do colégio. Olhei o público, sedento de música, e as mãos encravaram no teclado, os braços gelaram no fole do acordeão, nada me saiu. Foi preciso fechar o pano do palco e levar-me dali para fora, em estado de algidez.

De outra vez, estava uma trupe de ciganos romenos a tocar acordeão na Ribeira, com uma ranchada de miúdos a pedir dinheiro com caixas de esmolar improvisadas com garrafas de água cortadas a meio. Eu disse que não mereciam uma moeda, pois a tocatina era má, ou dito sem rodeios, era mesmo péssima. 0 cigano estendeu-me o acordeão, com um olhar desafiante. Eu sentei-me no banco e comecei a tocar, mal, como sei, mas ainda assim, soando como um virtuoso à beira dos gitanos romenos Tangido pelo orgulho, esgalhei Hey Jude, dos Beatles. Eles olharam para mim com um olhar estranho, entre testemunhas de acidente e génios de lâmpada. Foi um instante mágico, uma espécie de iluminação; logo de seguida, puseram-se em movimento e 
começaram a pedir esmola à minha volta. Algo de poderoso e encantatório tem a música, eu pecador me confesso, pois não consegui parar, por respeito à melodia, ao quarteto de Liverpool, ou por qualquer outro fenómeno cerebral convulsivo do domínio da epilepsia. Num instante, estava eu a arranhar HeY Jude na baixa do Porto, com uma trupe de ciganos a pedir dinheiro, uma cena pela qual eu podia ser chantageado, case alguém a tivesse registado para memória futura.

Hoje em dia, o acordeão serve-me de espanta-lapas: quando os amigos em fim de jantar alapam no sofá e nunca vêm a hora de ir embora de casa, eu vou buscar o acordeão, ameaço tocar, e a coisa resolve-se: tudo parte em debandada, pretextando uma pressa súbita, um ataque agudo de sono, a necessidade imperiosa de levantar muito cedo, ou qualquer outra desculpa para meter os ouvidos a salvo.

Tudo isto para dizer da minha absoluta inépcia para a música ou outras artes para além da escrita, esta arte maior.

Todas as artes se explicam e se socorrem da literatura e/ou da palavra.

A imortalidade dos textos, a parca necessidade de meios para criar para além da mente do escritor, a ubiquidade da literatura, a dimensão ilimitada do seu alcance, conferem-lhe essa superioridade que eu the atribuo.

Falando de Médicos:

Os médicos são imbuídos dos poderes de Esculápio, o deus grego e romano da medicina e da cura. (Também conhecido por Asclépio)

A versão mais corrente do mito de Esculápio refere que era filho de Apolo, um dos deuses que acumulava mais ministérios no Olimpo, e Corónis, uma mortal. Terá nascido de cesariana (após a morte da mãe) e terá sido levado pelo centauro Quiron, que o criou e educou na caça e na arte da cura, através do poder curativo das ervas e da cirurgia. Adquiriu tal habilidade na arte de curar, que conseguia fazer regressar os mortos à vida, o que causou grande ciúme em Zeus. 0 deus dos deuses tratou de o matar com um raio, acabando assim com a concorrência.

Esculápio curava os aleijados, os paralíticos e os que eram doentes de nascença. Feitos que mais tarde seriam também atribuídos a Jesus. Há estudos, como o de Gerald Hart, que traçam um paralelo entre a vida de Esculápio e a de Jesus: eram ambos filhos de um pai divino e uma mãe mortal e virgem, ligadas a maridos mortais, e foram ambos acusados por práticas e manifestações sobrenaturais.

O bastão de Esculápio, com uma serpente enrolada, ainda hoje é o símbolo dos médicos.

A relação de Esculápio com a serpente vem de uma lenda associada ao seu mito. Chamado a socorrer Glauco, que fora morto por um raio, uma serpente penetrou no aposento e Esculápio matou-a com o seu bastão. Nesse momento uma segunda serpente apareceu, trazendo um feixe de ervas na boca que depositou na boca da serpente morta, fazendo-a voltar à vida. Esculápio colocou as ervas boca de Glauco, que 
também ressuscitou. Desde esse momento, Esculápio fez da serpente o seu animal tutelar.

Há também interessantes artigos que apresentam uma explicação mais terrena para o bastão de Esculápio: a serpente tratar-se-ia não de uma víbora mas de um verme - o Dracunculus medinensis, conhecido por verme da Guiné, um parasita que na altura infestava com frequência os humanos. Encontraram-se infestações de dracunculose (ou dracunculíase) em múmias egípcias, o que atesta a prevalência desta parasitose na idade antiga. Ora o método de extração do verme do corpo humano, consiste em, quando o verme surge à pele numa bolha, enrolá-lo numa vara até o retirar do organismo.

Ainda hoje, esta e outras filarioses cutâneas são endémicas em África - A filariose Loa Loa, a Oncocercose ou cegueira dos Rios, por exemplo.

Realidade ou ficção, a verdade é que o bastão de Esculápio com a serpente enrolada tornou-se o símbolo da Medicina em todo o Mundo e está presente na bandeira da Organização Mundial de Saúde.

As reflexões sobre a simbiose entre Medicina e Literatura são profusas e recorrentes.

Parecem basear-se na falácia seguinte:

Há muito médicos escritores.

Nada de mais enganoso e ilusório. Demonstra-se com facilidade que esta premissa não corresponde a qualquer realidade factual. Na realidade, há poucos médicos escritores.

Esta ilusão reside no facto de conseguirmos facilmente nomear, no passado, vários bons escritores que eram médicos.

Surgem logo, para início de conversa, os nomes de Tchekov e Guimarães Rosa; e os nacionais: Amato Lusitano, Manuel Laranjeira, Júlio Dinis, Bernardo Santareno, Fernando Namora, Miguel Torga, Fialho de Almeida, João de Araújo Correia, Bento da Cruz, Lobo Antunes. O próprio Camilo Castelo Branco cursou Medicina, embora a sua boémia militante não the tivesse permitido acabar o curso. Restou da sua passagem pela Faculdade de Medicina do Porto, no seu museu Maximiano Lemos, um exemplar dos óculos de Camilo que ficaram por lá enquanto o escritor cabulava, nunca tendo passado dos primeiros anos do curso. Este vestígio não é original, pois há uma profusão de óculos de Camilo semeados por vários locais onde ele se despojaria de adereços para atividades que não se conhecem ao certo, mas se imaginam, dada a propensão libidinosa do escritor.

Se olharmos para o panorama literário actual, quantos são os escritores ficcionistas que estão presentes no mercado, nas editoras e livrarias tradicionais, e que são médicos em plena atividade clínica?

Contam-se pelos dedos de uma mão e sobram dedos. 
Salta logo à liça o nome de António Lobo Antunes. Acontece que deixou de exercer Medicina desde 1985 - há 34 anos.

É também conhecido Daniel Sampaio - mas a sua obra é de ensaio, muito sobre o âmbito da sua actividade como psiquiatra. Não é propriamente um ficcionista.

Temos também dois grandes poetas - Jorge Sousa Braga e João Luís Barreto Guimarães. Dois grandes vultos da poesia portuguesa contemporânea. Jorge Sousa Braga é especialista em Ginecologia e Obstetrícia, especializado em infertilidade, fertilização in vitro, inseminação artificial, e João Luís Barreto Guimarães é especialista em Cirurgia Plástica e Reconstrutiva. Estes dois casos devem ser considerados à parte, por reunirem características especiais: Não são ficcionistas, são poetas puros e dedicam-se a especialidades de alta tecnologia e sofisticação, o que não é muito usual acontecer quando falamos de escritores médicos - é mais frequente serem oriundos de especialidades mais globais, holísticas, como a Medicina Geral ou a Psiquiatria.

Esta seria uma discussão interessante: haverá alguma razão para que os escritores médicos ficcionistas sejam das especialidades médicas que vêm o doente como um todo, e os poetas médicos sejam oriundos de especialidades muito técnicas, que se especializam só num órgão ou sistema?

Não temos casuística que escore esta tese, pode e deve tratar-se de uma coincidência e de estarmos a falar de uma amostra de pequenos números.

Temos também o caso de Júlio Machado Vaz, psiquiatra com várias obras de ficção publicadas. Um excelente ficcionista.

Há também José Luís Pio Abreu, psiquiatra, com algumas obras de ficção publicadas.

Há ainda José Alves, pneumologista, que tem também alguns romances publicados.

Há também o caso do autor desta comunicação, que exerce Medicina Geral e publica ficção regularmente desde 1992.

Estes são os casos mais salientes de exercício em simultâneo das atividades de médico e de escritor, publicados em editoras do mercado e falados pela crítica.

\section{Porque escrevem os médicos?}

Essa é uma interrogação recorrente. Parte-se do princípio que há uma razão oculta e insidiosa que impele um médico a dedicar-se à literatura, no ramo de escritor. E que essa pulsão secreta terá forçosamente uma conexão de causa-efeito com a sua arte médica.

Este é um preconceito como outro qualquer.

Porque escrevem então os médicos?

De onde lhes vem a inspiração?

A escrita sai-lhes à custa de inspiração ou de transpiração?

A inspiração de um médico, enquanto escritor, será mais um caso de transfusão 
(dos universos que toma conhecimento, para o tubo de ensaio da escrita)?

Esta trasfega de mundos e vivências resume o processo criativo do escritor enquanto médico? Será possível ou desejável resistir ou ceder a este transvase?

Afinal, por qual motivo obscuro os médicos escrevem?

Podemos listar algumas hipóteses de razões que impelem os médicos a escrever:

Por catarse?

Por fuga a um quotidiano tedioso ou violento?

Por necessidade de relatar ao mundo um quotidiano demasiado rico para não ser partilhado?

A definição mais interessante que encontrei, embora não concorde com ela, é de um médico brasileiro, que diz o seguinte:

Como os médicos são uns perdedores, escrevem livros para criar pessoas imortais; porque as que tratam, morrem.

Supor que um escritor, se trabalha como médico, tenderá a exercer por via da escrita uma catarse das vicissitudes, anfractuosidades e traumas da sua vida clínica, é uma presunção sem qualquer base.

Como arte de fuga a um quotidiano tenso e de pressão, a profissão de escritor é pouco eficaz. A dedicação a atividades físicas como desportos vários, o mergulho com garrafas, a corrida e o ténis, ocorrem com muita frequência entre a classe médica - de forma exponencialmente mais frequente que a dedicação à escrita. E dentro das artes, há uma profusão de pintores, escultores, músicos e cantores, que suplantam em número de muito longe os que se dedicam à atividade da escrita.

A explicação para a maior apetência para outras artes e atividades em detrimento da escrita, deve estar na vontade de evasão do quotidiano. Se atentarmos no que é hoje a profissão médica, que passa a maior parte do seu tempo sentado, a escrever no computador, perante o doente, ou a atualizar-se, sentado ao computador, percebemos que são raros os que fazem da sua segunda vida sentar-se de novo ao computador a escrever, horas a fio.

Eu suponho que os médicos que são escritores, se dedicam à escrita porque gostam mesmo muito de o fazer - descobriram dentro de si esse dom e gostam de o trabalhar e aperfeiçoar. Ponto final parágrafo.

Todas as outras explicações e ilações são fantasias falaciosas, alicerçadas no tal erro de paralaxe causado por haver um punhado de bons escritores, com grande destaque, que eram médicos.

E na tal presunção da tal superioridade da Medicina, que supostamente confere poderes paranormais aos médicos. Então, se aceitaria que a propensão para a escrita faria parte destes superpoderes. É obviamente uma conclusão abusiva.

A Medicina é a mais humanista das ciências e a mais científica das Humanidades - dizia o filósofo Edmund Pellegrino. 
Quem professa e exerce Medicina, já terá provavelmente um pendor humanista dentro de si. E em alguns, também uma tendência para a expressão artística.

Não é a Medicina que leva à escrita. Mas a Medicina, enquanto ciência humanista (às vezes descrita como Arte Médica) coabita frequentemente com várias formas de expressão artística, entre elas a escrita. O conhecimento do indivíduo e do mundo que a Medicina proporciona, poderá ter um efeito de indução ou potenciamento de dons artísticos pré-existentes dentro do clínico. É fácil de aceitar que assim seja.

O que já não é aceitável é inferir que o exercício da profissão médica, se o médico também for escritor, o fará atingir os mais altos voos.

Atente-se neste facto:

A academia sueca atribui o prémio Nobel da Literatura desde 1901. Ao longo destes anos, de entre os II5 laureados não há um único médico e escritor.

A maior aproximação é o caso de Camilo José Cela, laureado com o Nobel da Literatura em 1989, que começou o curso de Medicina na Universidade Complutense - mas não passou do IO ano. Trabalhou como jornalista.

Esta constatação vale o que vale, mas é uma realidade factual que merece reflexão.

\section{Quando os médicos escrevem, o que escrevem?}

Há quem divida o campo em escritores médicos e médicos escritores.

É mais uma divisão artificial que confunde mais do que esclarece.

Parece-me mais adequado falarmos de médico e escritor, quando nos referimos a alguém que possui estas duas actividades. Sem dar primazia a qualquer delas.

Mas há dois grandes grupos em que podemos dividir os que acumulam estas duas funções:

- Há alguns clínicos que escrevem textos do tipo “retalhos da vida de um médico". Mais ou menos ficcionados, são textos de testemunho, com pendor auto-biográfico, que poderão ter algum interesse antropológico mas cujo voo literário é habitualmente curto, salvo raras e honrosas exceções.

Estando já este estilo esgotado nos "Retalhos da vida de um médico", que tão bem foram escritos por Fernando Namora, revisitar o género torna-se deslocado e redundante. $\mathrm{O}$ que poderia ser de alguma riqueza, revela-se por vezes empobrecedor e limitado.

- E há outros escritores simultaneamente médicos cujo universo ficcional nada tem a ver com a sua prática clínica. Este último grupo é aquele a que se apropria mais a definição de escritor e médico, não escritor médico ou médico escritor.

Há outra ideia feita que convém desmontar:

Há uma vantagem para o escritor, se este for médico

Este postulado baseia-se nestas suposições:

Como médico, o escritor tem acesso a múltiplas histórias de vida: dramas, paixões, 
vinganças, ódios. Casamentos e divórcios atribulados, casos de estupro, violência doméstica, amor incondicional; Conhece vidas, famílias. Este material servir-lhe-á para alimentar os textos literários, sem precisar de grande pesquisa ou imaginação.

Como médico e escritor tem uma visibilidade e aprovação social que lhe garantirá pelo menos, meio sucesso mediático, como escritor.

Nada de mais enganoso.

Na verdade, há uma grande desvantagem para o escritor, se este for médico.

Tendo, na realidade, acesso a um manancial de histórias pessoais de muito interesse, o que acontece é que este, sendo médico em plena atividade clínica, não as pode contar ou reproduzir - por uma questão de ética médica e por respeito à privacidade dos seus doentes. Se um doente reconhecesse a sua história íntima descrita em livro pelo seu médico, enquanto escritor, seguramente trataria de o processar. Ao médico e escritor está vedado contar histórias que conhece e que às vezes são prodigiosas, e mereciam fazer parte de um romance, pela limitação ética da profissão médica. Isso não aconteceria se o escritor não fosse médico, se tivesse outra profissão qualquer ou fosse só escritor.

Por isso, compreende-se que por esta limitação há mesmo uma desvantagem para o escritor, se este for médico.

Mas o médico e escritor, juntando em si o melhor destes dois mundos, não terá, só por esta associação virtuosa, o sucesso garantido na Literatura, e até na Medicina?

Mais uma vez, trata-se de uma falácia.

As duplicações de funções são menorizadoras, não elevadoras.

A profissão médica é marcante na vida de um indivíduo. Quando ele é também escritor, é difícil ser levado a sério, nos primeiros tempos. Por isso the chamam médico escritor - é um médico que também escreve nas horas vagas. Escreve uma coisas...

Não faltará quem diga: ele é bom médico. Escreve umas coisitas, mas não sei se...

O contrário também acontece. Dirão: é um bom escritor. Mas como médico, não sei, não... Sempre com a cabeça noutro lado, a pensar nos livros, não deve ser grande médico.

Fiquem-se com esta certeza: ser médico e escritor é mesmo difícil. E ser levado a sério em cada uma destas artes quando esta duplicação se verifica, também o é.

Para Torga, Namora e João Araújo Correia, o tempo da Medicina escorria mais lento do que hoje em dia. A evolução tecnológica da Medicina tem sido galopante.

A evolução das técnicas de diagnóstico e terapêutica, a profusão de artigos de investigação sobre as mais diversas áreas da ciência médica, obrigam a constante actualização. É a área profissional que sofre a mais acelerada transformação do seu «modus operandi». Compare-se, por exemplo, a evolução (ou falta dela) na Engenharia Civil e na Medicina: a técnica de construção de uma casa ou prédio hoje não difere muito das técnicas de construção de há cinquenta anos, enquanto que na Medicina, tudo mudou: atente-se na Cirurgia Cardíaca, no tratamento e o diagnóstico precoce 
do cancro, da hipertensão arterial, da Diabetes ou de qualquer outra doença, que sofreram uma evolução galopante. Os exames complementares de diagnóstico e terapêutica sofreram uma autêntica revolução. Os exemplos desta diversidade, multiplicidade e evolução galopante são tão bastos que se dispensa a sua enumeração (Gamagrafia, elastografia, Pet Scan, cápsula endoscópica, colangio-pancreatografia retrógrada endoscópica, ecocardiograma trans-esofágico, termografia, são alguns dos novos palavrões do léxico médico). Esta evolução científica constante obriga os médicos a grande esforço de actualização permanente.

É mesmo um milagre que um médico em plena actividade clínica consiga ser simultaneamente um escritor em plena pujança literária. É uma quase impossibilidade física, devido às imensas sobrecargas de trabalho e de tempo que é preciso dedicar a estas duas actividades.

Infelizmente esta parafernália diagnóstica e terapêutica, além de obrigar a um esforço olímpico de atualização, retira cada vez mais tempo ao médico para estar com o doente - ouvi-lo, percebê-lo, fazer-se ouvir e entender.

0 médico dos dias de hoje além do acrescido trabalho de formação contínua, nas mais diversas áreas, tem de fazer em cada consulta o esforço não menos olímpico para ter o tempo certo de que cada pessoa doente necessita - e de que ele necessita para entender o doente.

Os médicos de hoje são funâmbulos, equilibrando o tempo na corda tensa de uma consulta.

Estão longe, muito longe, os médicos João Semana que não tinham estes espartilhos de tempo, nem a vertigem da evolução médica.

Eu tenho o privilégio de exercer estas duas artes: a Medicina e a Escrita. São coisas diferentes e estanques, uma não depende da outra, não se condicionam nem conflituam. Contaminam-se na medida em que o fautor é o mesmo, e lá haverá um cunho pessoal em uma e outra.

Costumo dizer que sou médico de dia e escritor de noite. É uma simplificação, condenada a ser desmentida. Representa, além da dissociação temporal destas duas artes dentro de mim, um ritmo circadiano, uma bipolaridade, um alter-ego. Em semiologia clínica, esta coisa do alter-ego poderá ser uma entidade patológica e tratar-se de um distúrbio dissociativo de personalidade. Visto à luz da literatura, torna-se benigno e criativo.

Não me queixo desta falta de tempo que atrás referi, embora a observe e por vezes a sinta. Se tivesse mais tempo, não escreveria mais nem melhor. Viajaria mais e talvez isso rasgasse outros horizontes literários e me inspirasse.

Não é fácil vestir estas duas peles - de médico e de escritor. Se é fácil despir a pele das personagens literárias, a pele de médico não descola do escritor. Viver com duas peles e duas vidas é ter um gémeo siamês colado a nós, inseparável.

As minhas inspirações e transfusões vêm das minhas vivências, das viagens, do 
que ouço, vejo e sinto. Como médico, lido com muitas pessoas de todas as classes sociais, visito-lhes o interior da casa, da família, da mente e do corpo. Por restrição ética, estou impedido de contar o que me revelam no confessionário do consultório. Mesmo assim, sinto-me autorizado a roubar um nome, um tique, um olhar. Que me lembre em todos os livros que escrevi (uns 23) apenas 3 histórias foram importadas do universo dos meus doentes: dois contos e um romance. E há também dois nomes roubados. Isto não só pela castração da ética médica, mas também porque gosto mais de construir histórias e personagens novas, diferentes. Não me satisfaz apenas importá-las da realidade. Estatisticamente falando, o peso relativo do meu universo médico na minha escrita é muito pouco relevante. Mas existe. Sobretudo nos meus livros policiais, onde a profissão médica me é muito útil para inventar processos de assassinato quase perfeitos.

A inspiração (ou a transfusão) vem de todo o lado. O escritor é um predador, cleptomaníaco, em permanente trabalho de escuta. No que me diz respeito, posso recordar-me de uma conversa com o João Luís Barreto Guimarães, ao jantar, que resultou num romance. E uma conversa líquida com o Manuel António Pina a celebrar o prémio Camões (que é um prémio liquido, bebe-se bem) que resultou em outro romance. E o manancial de histórias ouvidas à minha sogra em relatos de volframistas e retratos pícaros de aldeia, que resultaram em outro romance.

Termino, com um aviso:

Os médicos e escritores são seres raros e estranhos. Se virem um, observem-no com cuidado, a confortável distância. Nunca se sabe do que são capazes. Tanto nos podem descobrir uma doença, como num ápice, meterem-nos dentro de um livro, dando corpo a uma personagem.

Por isso, todo o cuidado com eles, é pouco.

\section{Nota}

\footnotetext{
* Miguel Miranda é um escritor português, médico de profissão. Nasceu na cidade do Porto. Escreve contos, romances e livros policiais. Recebeu vários prémios literários, como o Grande Prémio do conto APE, o Prémio Caminho de Literatura Policial, o Prémio Fialho de Almeida em duas edições. Foi finalista do Prémio PEN de Narrativa e finalista do Prémio Violeta Negra do Festival de Literatura Policial de Toulouse. Está editado em França, Itália, Brasil e México. O humor, a ironia, o insólito e algum surrealismo são marcas da sua escrita. A sua escrita é marcada pelas reflexões sobre a sociedade do tempo presente ou do passado recente - desde os retratos de um certo Portugal ( $O$ Rei do Volfrâmio, $O$ Silêncio das Carpideiras) - aos retratos de um certo Mundo, formando segundo o Autor, uma «Trilogia do Caos» (A Paixão de K, Todas as Cores do Vento e Demasiado Mar para Tantas Dúvidas).
} 